\title{
Higher Education in Latin America: Trends and Explanations
}

\author{
Miguel Székely \\ Director, Center for Education and Social Studies
}

Received: June 7, 2017 Accepted: July 23, 2017 Published: August 1, 2017

doi:10.5296/jse.v7i3.11361 URL: https://doi.org/10.5296/jse.v7i3.11361

\begin{abstract}
This paper documents the recent trends in access and completion of higher education (HE) in 18 Latin American countries, and explores the relation with a series of context variables in order to verify different hypothesis about the changes observed. We find that access to HE among individuals in the working age population has risen in the region, while completion rates have fallen. Our cohort-level analysis shows that the recent expansion in HE enrollment has been mostly associated with the increase in Upper Secondary completion rates as opposed to an increase in the fraction of USE graduates who enroll in HE. Other factors associated with this expansion include economic growth and favorable labor market conditions. Nonetheless, the dominant role of "the pipeline" underscores the need to continue increasing USE completion in order to expand HE access. Since "the pipeline" effect will at some point exhaust its role driving HE expansion, our findings also underscore the need for policies that raise the enrollment of USE graduates.
\end{abstract}

Keywords: Higher education, growth, labor markets 


\section{Introduction}

In the past decades, school enrollment in basic education in Latin America (LAM) has experienced substantial progress. Based on household survey data, the cohort born in 1950 was the first to surpass an average of six years of schooling, roughly equivalent to completing primary education(Adelman and Székely, 2015), and the cohort born in 1975 was the first to surpass an average of nine years of schooling, roughly equivalent to completing lower secondary education (LSE). (Note 1)

According to the same data, the cohorts that are currently exiting secondary school age (born approximately in 1995-1998) have completed on average 11.5 years of education. While this reflects a substantial expansion in Upper Secondary Education (USE), it implies that, on average, youth fall short of completing the 12-year cycle usually required to graduate from USE and become eligible for Higher Education (HE).

This state of affairs is largely due to high dropout rates from USE, (Note 2) which have risen to about 25 percent in recent years (Bentaouet-Kattan and Székely 2015). (Note 3) These high dropout rates constitute a bottleneck for educational progress in LAM and compromise the region's long-term prospects given HE's critical role in the generation of skilled labor for the knowledge economy, the promotion of scientific discovery and technological innovation, the adoption and use of new technologies, and the growth of productivity and competitiveness. (Note 4)

In this paper we document the region's recent trends in access (Note 5) and completion of higher education by relying on household surveys from 18 countries, and we explore the relation with a series of context variables in order to verify different hypothesis about the changes observed.

Household surveys have a number of desirable features for our purposes. (Note 6) They sample households from the whole population of a country, whereas educational administrative records usually cover individuals enrolled in the school system during their school years. By covering individuals of all ages, household surveys provide information on post-school outcomes such as employment and earnings. While high-quality educational data in the region has been collected only recently, and just for a few countries, household surveys have been conducted for at least twenty years in most of the region, thus allowing for the analysis of trends and cross-country comparisons. Further, by combining institutional data from the countries' HE authorities with household survey data we are able to classify HE programs into academic and technical (more details are provided below).

We document that access to HE among individuals in the working age population (WAP) has risen in the last 20 years, from approximately 15 to 20 percent, as the younger cohorts have had greater access to HE. Most of the growth in HE access has taken place via academic programs, which account for about 80 percent of total HE enrollment. Importantly, while HE enrollment has grown in the region, HE completion rates have actually fallen.

We also document the economic advantages associated to HE enrollment in terms of overall employment, employment in the formal sector, wages, and position in the income distribution. 
Further, completion of HE improves these outcomes relative to mere enrollment (without completion) of $\mathrm{HE}$, a fact that calls attention to the declining completion rates.

Our cohort-level analysis shows that the recent expansion in HE enrollment has been mostly associated with the increase in USE completion rates as opposed to an increase in the fraction of USE graduates who enroll in HE. In other words, enlarging the "pipeline" of eligible students for HE has been a critical driver of the recent expansion in HE.

Other factors associated with this expansion include economic growth and favorable labor market conditions. Nonetheless, the dominant role of "the pipeline" underscores the need to continue increasing USE completion in order to expand HE access. Since "the pipeline" expansion will at some point exhaust its role driving HE expansion, our findings also underscore the need for policies that raise the enrollment of USE graduates.

The paper is structured as follows. Section 1 introduces the data and definitions. Section 2 presents the main stylized facts and trends in HE access in the region. Section 3 describes some economic outcomes associated to HE access, while Section 4 examines some correlates of HE growth in the region. Section 5 concludes.

\section{Data and definitions}

As in other regions in the world, in LAM there are multiple educational options after USE. We group them into two broad categories. The first comprises training programs, apprenticeships, courses and specializations that may not require completed USE as a pre-requisite for enrollment and do not lead to an official professional degree, and are thus not considered part of the HE system. The second comprises structured programs that require the following: (i)completed USE as a pre-requisite for enrollment;(ii) official recognition by the education authorities as a HE program; and (iii) the award of an officially recognized professional degree or certificate after completing the program's academic requirements. In this paper, HE consists of programs corresponding to the second category.

Within HE, two types of programs are common. The first consists of programs usually lasting 4-6 years offered by universities, academic institutions, education centers, institutes, etc. that lead to a professional degree. These are usually a pre-requisite for enrollment in post-graduate programs such as masters and doctorates. We refer to these programs as Academic HE (AHE).

The second consists of technical/vocational programs that usually last 1-3 years. The certificates awarded by these programs are not professional degrees but are officially recognized by the education authority as post-USE education. These programs are typically offered by institutions labeled as "technical" or "technological" although they are sometimes offered by other HE institutions as well. We refer to these programs as Technical HE (THE).

Household surveys in LAM are particularly well suited to identify HE choices. (Note 7) In the surveys, individuals usually report their completed years of schooling, highest educational level attained, and type of education acquired (AHE or THE in the case of HE). (Note 8) This 
makes it possible, for instance, to focus on those that enrolled in a particular program and distinguish between those who completed it, and those who did not. Since household surveys contain a wide variety of personal and household characteristics (such as gender, ethnicity, and household income), they allow us to study the association between HE access and those characteristics.

In this paper we use household surveys for 325 country-years and 18 countries in LAM between 1980 and 2013. Appendix Table A1 specifies the years used for each country. For survey respondents we identify the educational level and program type based on the above definitions.

Nine percent of the surveys are for the 1980-1989 period, 31 percent are for 1990-1999, and 60 percent are for 2000-2013. Brazil has the largest number of surveys (27 years), followed by Argentina (26), Costa Rica (25), Venezuela (23), Peru, Paraguay and El Salvador (21), Uruguay (19), Honduras (18), Bolivia, Ecuador and Colombia (17), Dominican Republic, Mexico, Panamá and Chile (14), Guatemala (10) and Nicaragua (7). The surveys are representative of the total population of each country, with the exception of Argentina and Bolivia for surveys prior to the 2000s, and of Uruguay, where the samples are for urban areas only. (Note 9)

It is important to note that each country produces these data using different formats, questionnaires, codes and definitions (see Deaton 2017), but since we have access to the original survey data we are able to standardize the relevant variables to achieve comparability within and across countries, and over time. Importantly, we take into account that countries vary in the length of primary, lower secondary and upper secondary education, and thus in the age at which individuals become eligible for HE. (Note 10) Among respondents who have ever enrolled in HE we can separately identify AHE and THE enrollment in all countries except Brazil and Guatemala. 


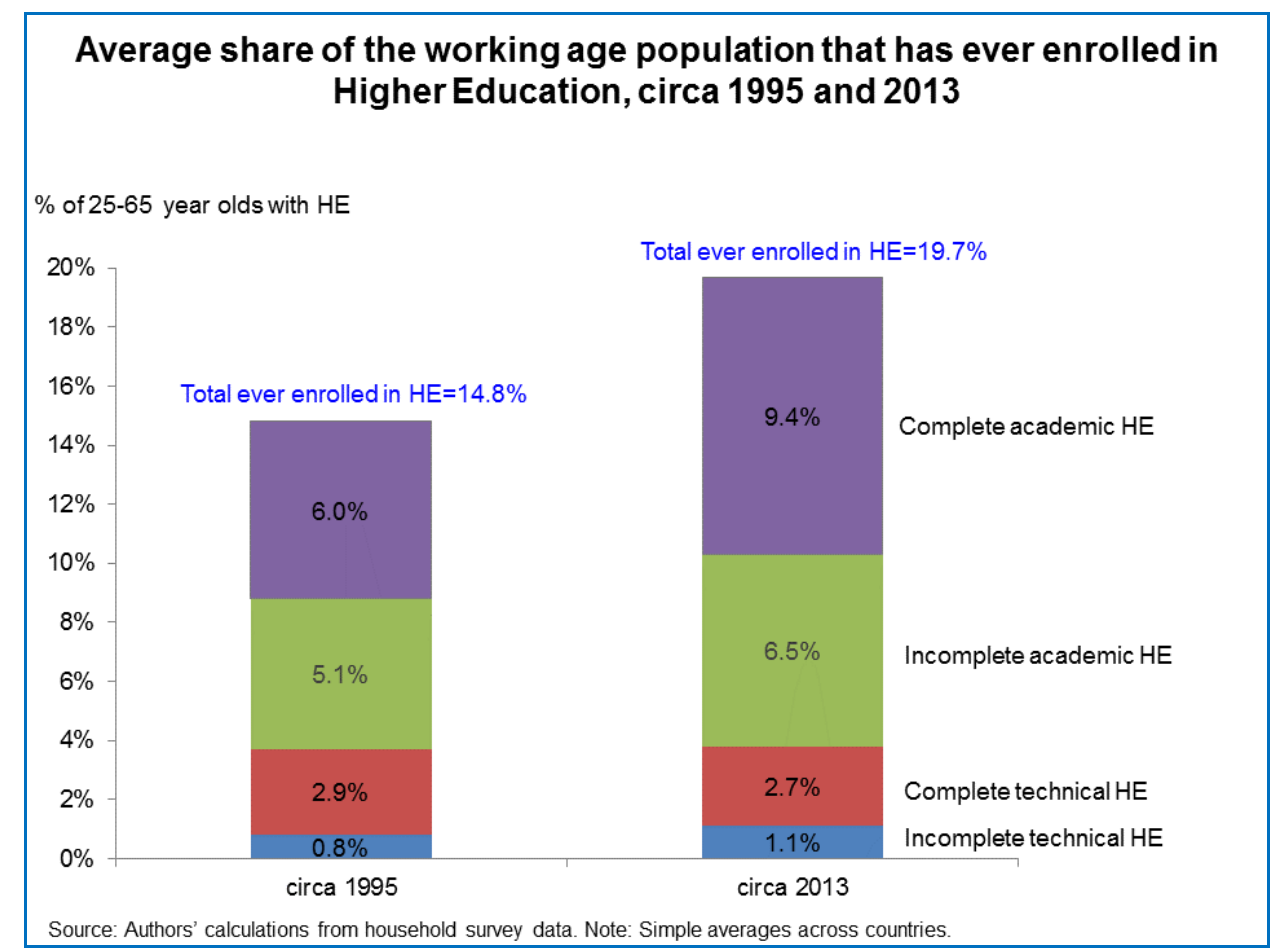

Figure 1.

\section{Stylized facts and trends of higher education in Latin America}

In this section we exploit convenient features of household survey data to analyze recent trends of HE in LAM. We begin by providing a snapshot of the educational composition of the population aged 25-65 (i.e., the working age population, henceforth WAP) circa 1995 and 2013. Then we examine the youngest and older cohorts within the WAP in 2013 -aged 25-29 and 60-65 respectively- to compare educational attainment (i.e., the highest educational level completed) between them. To gain insights on the flow of individuals into HE and its changes over time, we examine a young and a middle-aged cohort (aged 23-25 and 40-42 in 2013, respectively). In all cases, when presenting regional figures, we include unweighted country averages.

\subsection{Changes in higher education access in the working age population over time}

We start by comparing the proportion of individuals that have ever enrolled in HE (i.e., those who have ever enrolled in HE, regardless of whether they finished) in the WAP in 1995 and 2013 (Figure 1). (Note 11) This provides a first answer as to whether the region has increased the stock of WAP with at least some HE (Note 12) over the last two decades.

As the figure shows, in 2013on average 19.7percent of the WAP has at least some HE, disaggregated as follows: 9.4 percent of the WAP has complete AHE (i.e., they enrolled in a program and completed it), 6.5 percent has incomplete AHE (i.e., they enrolled in a program but did not complete it), 2.7 percent has complete THE, and 1.1 percent has incomplete THE. Thus, 81 and 19 percent of those enrolled in HE chose the academic and technical track, respectively. (Note 13) 
The figure also shows that in 1995, 15 percent of the WAP had at least some HE. Thus, over the last two decades the stock of WAP with at least some HE has grown by 4.7 percentage points -about 2.3percentage points per decade. Interestingly, this growth is almost totally due to AHE, and is almost equal to the increase in the fraction of individuals with complete AHE. Nonetheless, while the share of individuals with incomplete THE has barely changed between the two years, the share of individuals with incomplete AHE has risen.

Table 1. Share of working age population that have ever enrolled in HE in Latin America, circa 1995 and 2013

\begin{tabular}{|c|c|c|c|c|c|c|c|}
\hline \multirow[b]{2}{*}{ Country } & \multicolumn{2}{|c|}{$\%$ that Accessed HE } & \multicolumn{2}{|c|}{$\%$ in 2013 that Completed HE } & \multicolumn{2}{|c|}{$\%$ by HE modality } & \multirow{2}{*}{$\begin{array}{c}\% \text { of increase } \\
\text { Due to } \\
\text { enrollemnt in } \\
\text { AHE }\end{array}$} \\
\hline & Circa 1995 & Circa 2013 & $\begin{array}{c}\text { did not complete } \\
\text { HE }\end{array}$ & Completed HE & Academic & Technical & \\
\hline Argentina & $13,3 \%$ & $32,0 \%$ & $12,3 \%$ & $19,1 \%$ & $19,0 \%$ & $12,4 \%$ & $57,1 \%$ \\
\hline Bolivia & $23,8 \%$ & $22,6 \%$ & $11,2 \%$ & $10,8 \%$ & $16,7 \%$ & $5,2 \%$ & $84,3 \%$ \\
\hline Brasil & $7,9 \%$ & $11,9 \%$ & $0,0 \%$ & $11,3 \%$ & & & \\
\hline Chile & $14,7 \%$ & $23,8 \%$ & $6,8 \%$ & $16,4 \%$ & $15,1 \%$ & $8,0 \%$ & $93,3 \%$ \\
\hline Colombia & $19,5 \%$ & $24,4 \%$ & $10,7 \%$ & $13,1 \%$ & $21,8 \%$ & $8,0 \%$ & $54,8 \%$ \\
\hline CostaRica & $13,6 \%$ & $25,2 \%$ & $12,1 \%$ & $12,5 \%$ & $23,6 \%$ & $1,0 \%$ & $94,9 \%$ \\
\hline Ecuador & $17,3 \%$ & $22,7 \%$ & $10,6 \%$ & $11,4 \%$ & $21,1 \%$ & $1,0 \%$ & $103,0 \%$ \\
\hline ElSalvador & $8,6 \%$ & $8,9 \%$ & $2,5 \%$ & $5,8 \%$ & $8,2 \%$ & $0,1 \%$ & $100,0 \%$ \\
\hline Guatemala & $7,4 \%$ & $15,3 \%$ & $1,1 \%$ & $13,6 \%$ & & & \\
\hline Honduras & $5,5 \%$ & $5,9 \%$ & $1,2 \%$ & $4,1 \%$ & $5,1 \%$ & $0,2 \%$ & $89,4 \%$ \\
\hline Mexico & $11,7 \%$ & $16,5 \%$ & $3,3 \%$ & $12,6 \%$ & $14,9 \%$ & $1,0 \%$ & $92,8 \%$ \\
\hline Nicaragua & $7,7 \%$ & $15,2 \%$ & $4,8 \%$ & $9,9 \%$ & $13,8 \%$ & $0,8 \%$ & $98,0 \%$ \\
\hline Panama & $27,8 \%$ & $24,5 \%$ & $11,4 \%$ & $12,6 \%$ & $23,5 \%$ & $0,4 \%$ & $11,2 \%$ \\
\hline Paraguay & $14,4 \%$ & $15,3 \%$ & $6,4 \%$ & $8,3 \%$ & $13,3 \%$ & $1,4 \%$ & $77,1 \%$ \\
\hline Peru & $22,9 \%$ & $28,3 \%$ & $8,6 \%$ & $19,1 \%$ & $13,2 \%$ & $14,5 \%$ & $27,2 \%$ \\
\hline RDominicana & $15,8 \%$ & $18,9 \%$ & $6,9 \%$ & $11,3 \%$ & $18,0 \%$ & $0,2 \%$ & $112,9 \%$ \\
\hline Uruguay & $15,3 \%$ & $16,1 \%$ & $8,0 \%$ & $7,5 \%$ & $12,4 \%$ & $3,1 \%$ & $80,4 \%$ \\
\hline Venezuela & $14,6 \%$ & $26,7 \%$ & $6,8 \%$ & $19,3 \%$ & $18,0 \%$ & $8,1 \%$ & $75,7 \%$ \\
\hline Average & $15 \%$ & $19,7 \%$ & $7,6 \%$ & $12,1 \%$ & $16,1 \%$ & $4,1 \%$ & $78,3 \%$ \\
\hline
\end{tabular}

Source: Author's calculations from household survey data.

Table 1 disaggregates the information by country. It shows that as of 2013, the largest shares of WAP that have ever enrolled in HE are found in Argentina, Peru and Venezuela (above 25percent), while the lowest are found in Honduras, El Salvador, and Brazil (below 15 percent). The highest shares of WAP with complete HE are also found in Argentina, Peru and Venezuela (about 19 percent); the lowest are found in Honduras, El Salvador and Uruguay (between 5 and 8 percent). Between 1995 and 2013, the share of WAP with at least some HE grew the most in Argentina, Venezuela and Costa Rica, while it changed very little in Paraguay, Uruguay, Honduras, El Salvador, and Panama. As the table shows, the AHE track prevails in all countries except Peru. The only countries where THE represents more than 30 percent of the HE stock are Peru, Argentina, Colombia, Venezuela and Chile. The Table also 


\section{Macrothink}

shows (last column) that most of the increase in HE enrolment between 1995 and 2013 stemmed from the expansion in AHE -with the only exceptions of Peru and Panama, AHE expansion accounted for more than half of the increase in access to Higher Education.

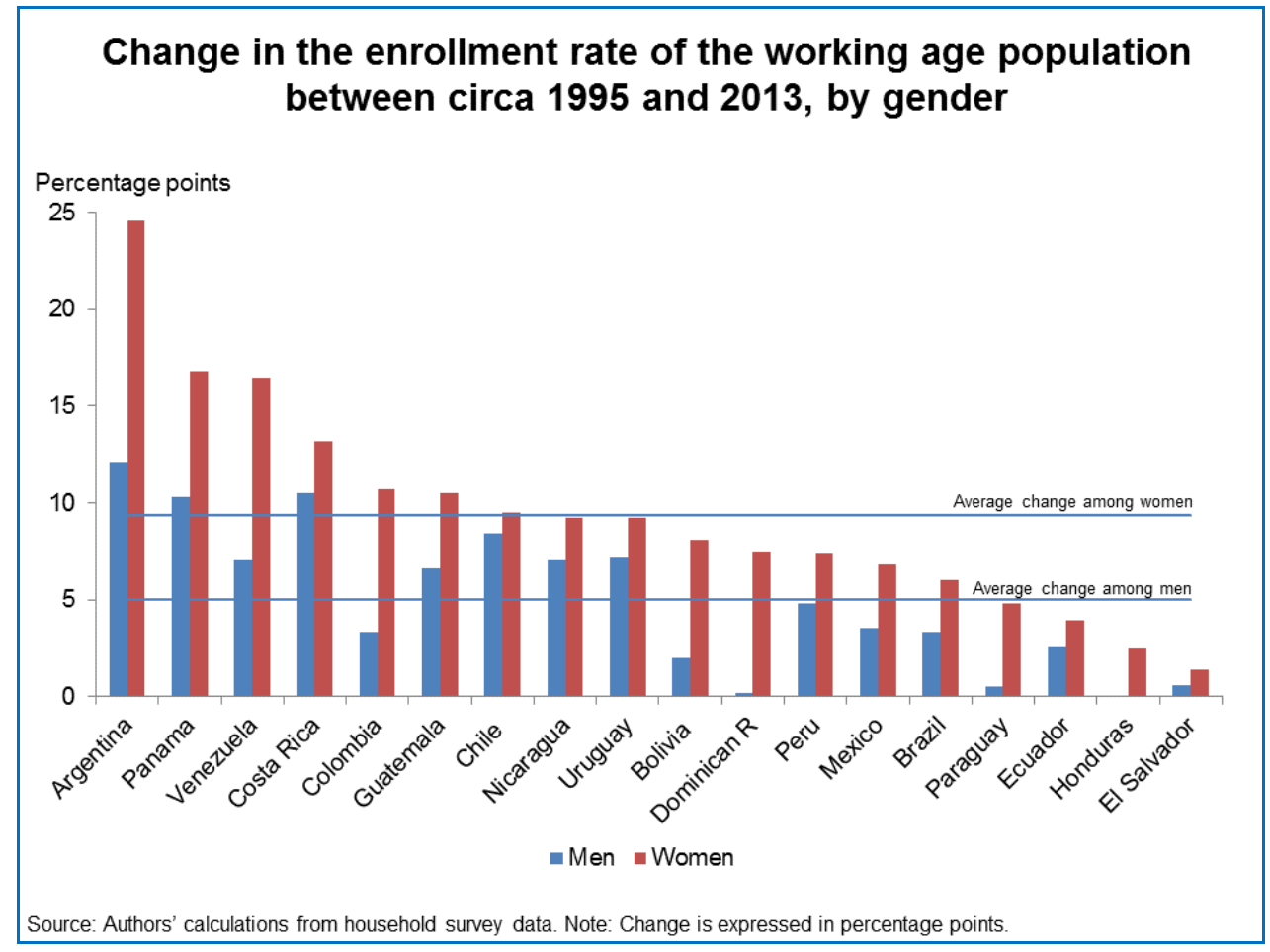

Figure 2.

Interestingly, the increase in the HE stock among the female WAP has almost doubled that of the male WAP (see Figure 2). The greatest female-male growth gap corresponds to Argentina, Panama, Venezuela, Colombia, Bolivia and the Dominican Republic. Within countries, males and female in the WAP have enrolled in AHE (as opposed to THE) at roughly the same rate. Further, among those in the WAP who started HE, females have been more likely to finish than males. The regional average completion rates for females as of 2013 reached 65.2 per cent, while it was of 62.4 per cent among males

When analyzing educational attainment for the WAP along the income distribution we find that, on average, almost 60 percent of the individuals in the richest income quintile have at least some HE, in contrast with 15 percent of individuals in the lowest income quintile. While this is no causal evidence of the effect of education on future income, it does indicate a positive correlation between the two.

These snapshots of HE enrollment and completion in the WAP taken 20 years apart are informative of changes in the WAP stock of skills. However, since the WAP is comprised of many different cohorts, the snapshots are not informative of flows into the stock. The next subsections explore this matter. 


\section{Macrothink}

\subsection{Cohort changes in HE enrollment and completion}

Since household surveys include individuals of all ages, they allow for an analysis of HE access over time by grouping individuals by their year of birth (their "cohort"), which is obtained from subtracting the survey year from the individuals' reported age. For instance, individuals in the household survey who report an age between 60 and 65 in 2013 can be assigned to the cohorts between 1948 and 1953 since these are their birth years (see Browning, et.al. (1985)). Given that household surveys report the number of years of schooling declared by the respondent and the highest educational level completed, we can determine the average educational attainment of each cohort. Given that individuals have usually finished their schooling by age 25 , following a cohort until approximately that age gives us a sense of its average school attainment. (Note 14) Thus, in this subsection we examine the two ends of the 2013 WAP - the cohort aged 25-30, and the cohort aged 60-65.

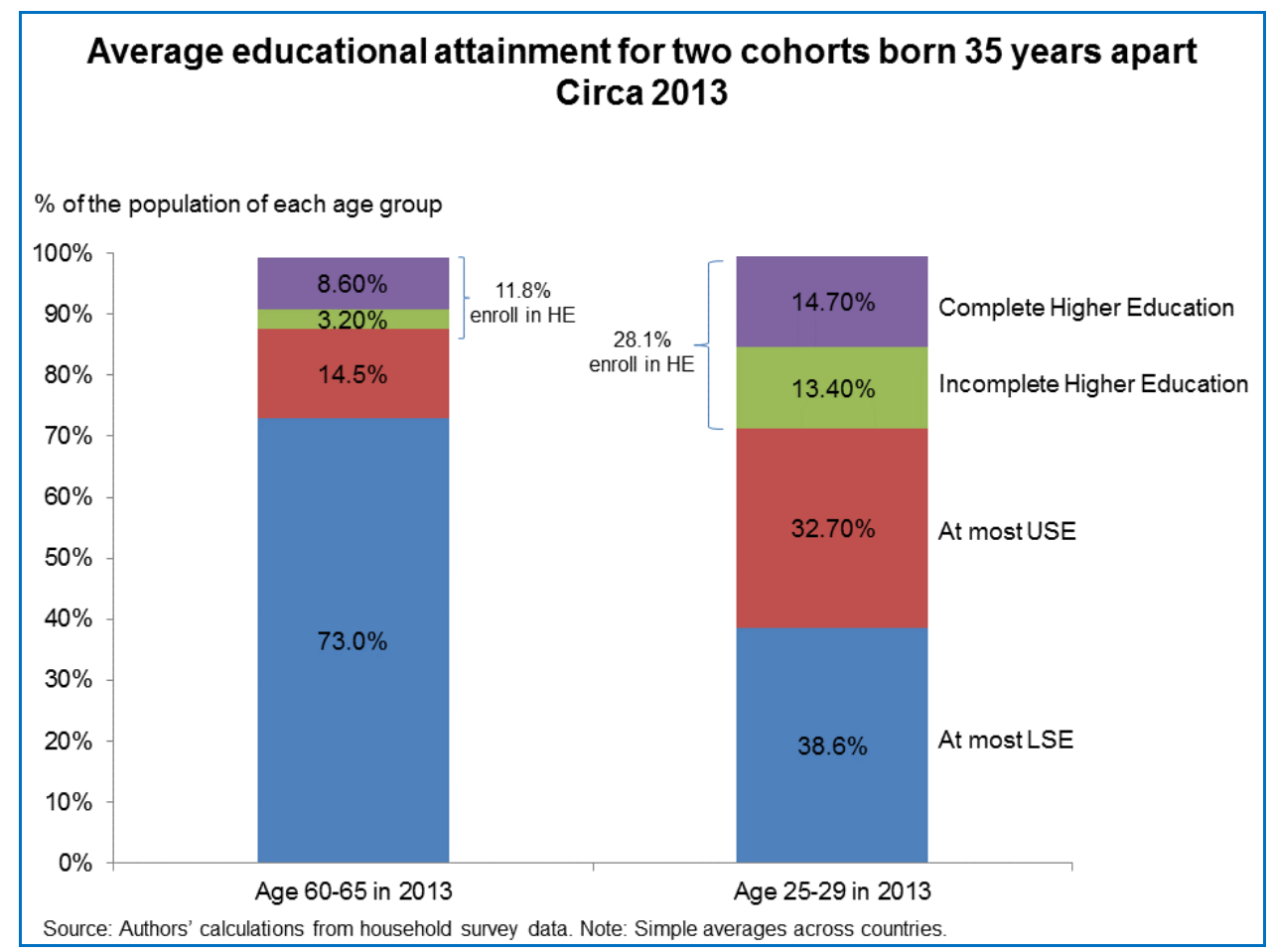

Figure 3.

As Figure 3 shows, among individuals in the 1948-1953 cohort (aged 60-65 in 2013), the highest educational level that individuals enrolled in (regardless of completion) was as follows: LSE for 73 percent of the cohort, USE for 14.5 percent, and HE for 11.8 percent. In contrast, among individuals born 35 years later (aged 25-30 in 2013), the highest educational level reached (regardless of completion) was higher, on average: LSE for 38.6 percent, USE for 32.7 percent, and HE for 28.1 percent. In other words, HE access is 16.4 percentage points higher for the younger cohort. 


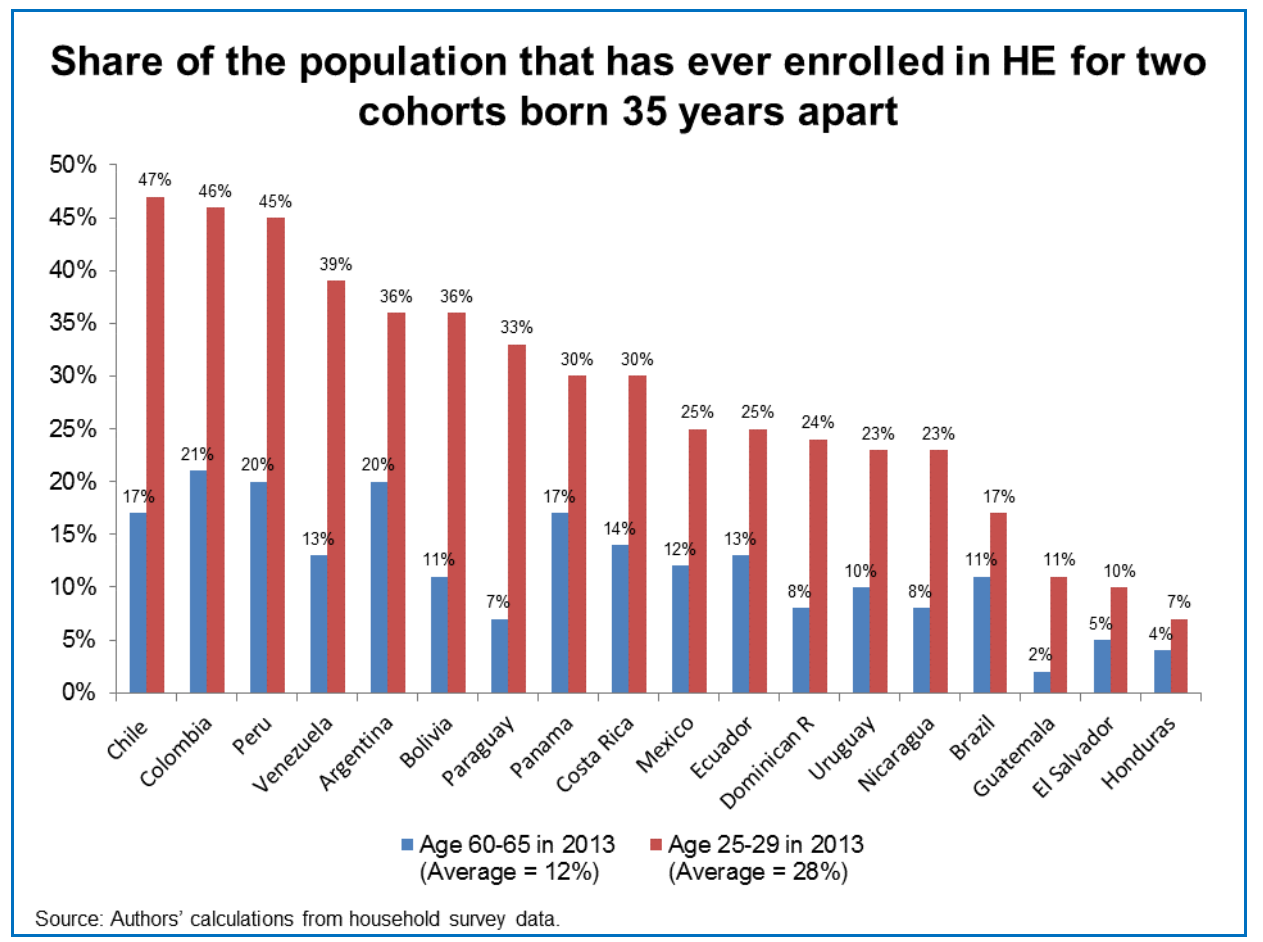

Figure 4.

For each country, Figure 4 shows the fraction of individuals from each of those cohorts who have ever enrolled in HE. For the younger cohort, the countries with the highest HE enrollment rates are Chile, Colombia and Peru with more than 40 per cent; the countries with the lowest rates are Brazil, Guatemala, El Salvador and Honduras with less than 20 per cent. In countries such as Chile, Colombia, Peru, Venezuela, Bolivia and Paraguay, the fraction of individuals who have ever enrolled in $\mathrm{HE}$ is at least 25 percentage points higher for the younger cohort.

As we return to Figure 3, we see an emerging challenge. Among those who were ever enrolled in HE, the fraction of those who finished is equal to 73 percent $(=8.6 * 100 / 11.8)$ for the older cohort, but is equal to only 52 percent $(=14.7 * 100 / 28.1)$ for the younger cohort. Most of these regional trends are explained by the dynamics of AHE, since around 85 per cent of HE enrollment in these two cohorts corresponds to this category-completion rates in AHE declined from 72 to 50.8 per cent across these cohorts, while completion rates in THE were reduced from 78.6 to 60.5 per cent.

For the younger cohort, Figure 5 shows the proportion of individuals who have enrolled in HE, and the proportions that completed and did not complete HE. For instance, in Chile 47 percent of the cohort has enrolled in HE; 27 percent of the cohort has completed HE and 20 percent has not completed HE. Thus, the completion rate for this cohort in Chile is equal to 57 percent $(=27 * 100 /(20+27))$, as indicated in the bar with completion rates above the figure. As the figure shows, Bolivia, Uruguay and the Dominican Republican have the lowest completion rates, whereas Brazil, Guatemala and Mexico have the highest. 


\section{Share of individuals aged 25-29 in 2013 who have ever enrolled in HE, by completion status}

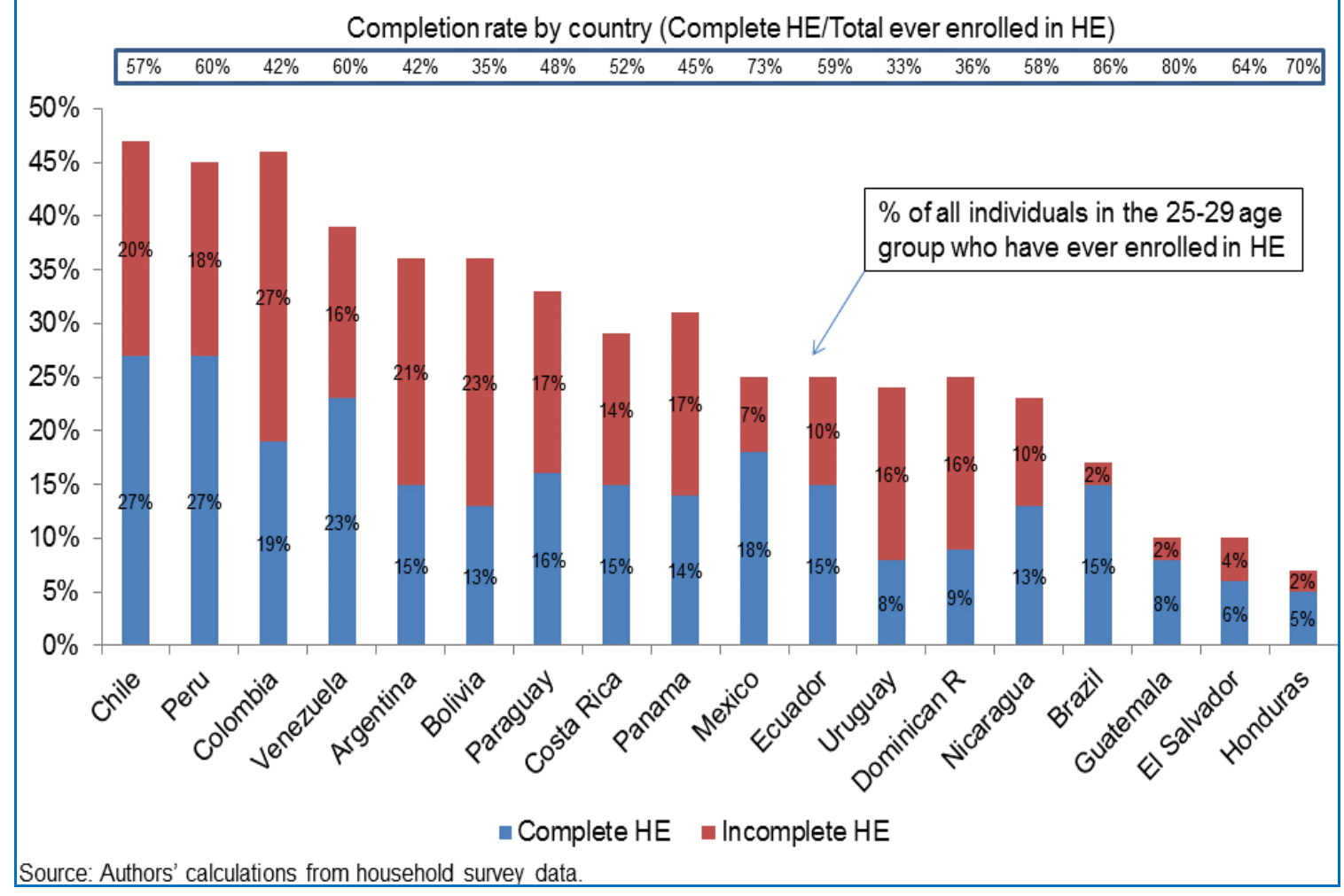

Note: the height of the vertical bar represents the percent of individuals in the 25-29 age group who have ever enrolled in HE.

Figure 5.

\subsection{Following cohorts over time}

The availability of repeated cross sections of household surveys allows us to track down the educational trajectory of representative groups of individuals belonging to a birth cohort. This, in turn, allows us to examine the cohort flow into the HE stock of the WAP. In what follows we use the term "enrollment rate" to denote the fraction of individuals of a given age who are enrolled in school.

Consider, for instance, the case of El Salvador, for which we have 19 years of survey data over a 24-year period. Consider individuals in the 6-11 age group (and hence of the $1978-1983$ cohort) in the first survey in 1989. Since individuals are randomly sampled every year, individuals in the 12-17 age group in 1995are used to build a "synthetic cohort" with those who were six years younger (i.e., 6-11) six years earlier (i.e, in 1989). This allows us to follow the behavior of individuals in the 1978-1983 cohort as they reach ages 12-17, when they are expected to attend LSE and USE. We continue building the cohort by using individuals aged 18-22 in 2001, and individuals aged 25-29 in 2008. For El Salvador, the cohort can be traced further into the 2013 survey, when individuals are aged 30-34 and thus beyond school age. By calculating the cohort's average enrollment rate, educational 
attainment and completed years of schooling at each point in time, we can trace out its full educational trajectory.

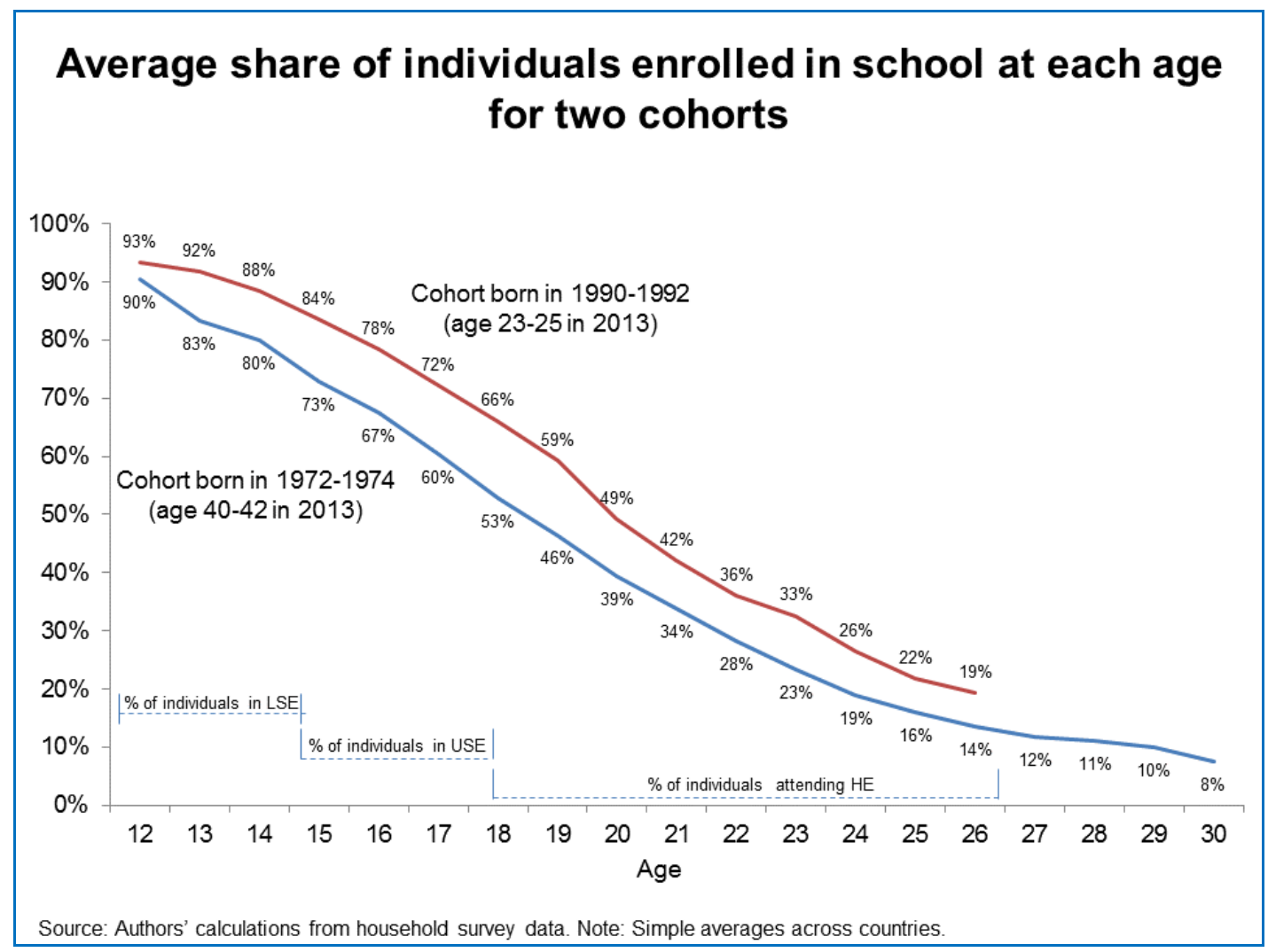

Figure 6.

Figure 6 displays the outcome of this exercise for two different cohorts. (Note 15) The first one was born in 1972-74 and is thus aged 40-42 in 2013 (we can follow this cohort for almost two full decades). The second was born eighteen years later, in 1990-92 and is thus 23-25 in 2013. The figure shows the fraction of individuals in each cohort who were enrolled in school at each age between 12 and 30. For instance, 90 percent of individuals in the older cohort were in school at age 12, but only 53 percent were in school at age 18. In contrast, 93 and 66 percent of individuals in the younger cohort were in school at ages 12 and 18 respectively.

As the figure shows, the younger cohort's profile lies above the older cohort's. This indicates that enrollment rates are higher at each age for the younger cohort. The vertical difference between the two profiles is the largest between ages 12 and 19, indicating that the greatest enrollment rate gains happened at LSE and USE ages. However, the vertical difference shrinks after age 19, which is when individuals would typically enter HE.

Further analysis shows thatonly 38 percent of the individuals in the 1972-74 cohort completed USE; (Note 16) of these, 58 percent enrolled in HE. In contrast, 52 percent of the individuals in the 1990-92 cohort completed USE. Despite this 14-percentage point gain in the USE completion rate, the percent of USE graduates that actually enrolled in HE (henceforth, the conditional HE enrollment rate) rose by only two percentage points (from 58 to 60 percent). In other words, most of the growth in the HE enrollment rate between the two 
cohorts would be due to an increase in USE completion rates rather than an increase in the conditional HE enrollment rate.

Figure 7 shows the changes in USE completion and HE conditional enrollment rates between the two cohorts for the different countries. With the exceptions of Argentina, Nicaragua and Uruguay the increases in USE completion rates are significantly above the increases in HE conditional enrollment rates. Moreover, in five countries (Bolivia, Brazil, the Dominican Republic, Honduras and Paraguay) the conditional enrollment rates fell in the context of an USE graduation expansion.

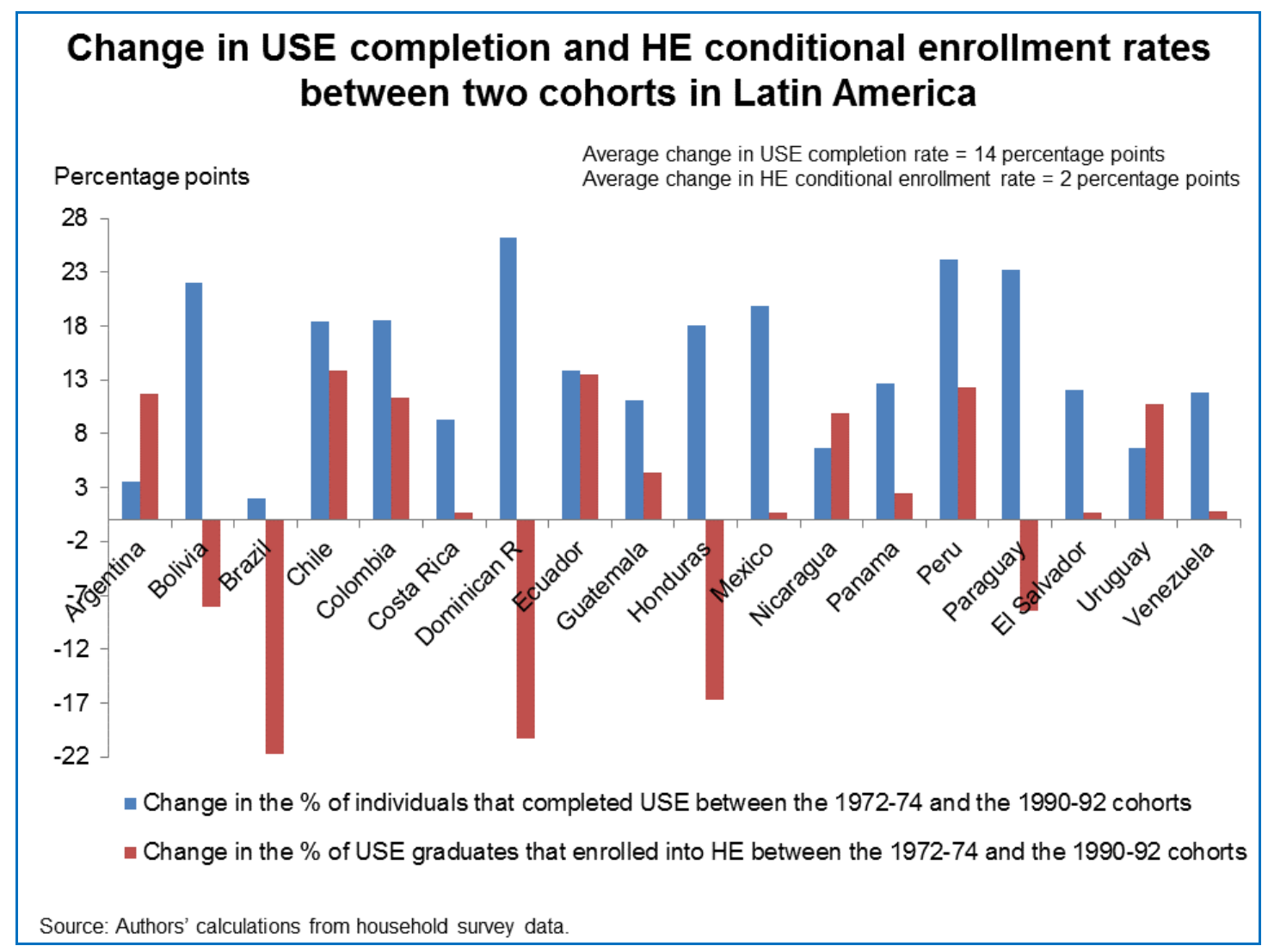

Note: USE completion rate is the percent of individuals who completed USE relative to those who started it. Conditional enrollment rate is calculated as the percent of individuals who have ever enrolled in HE relative to those who graduated from USE.

Figure 7.

While HE access has broadened for recent cohorts, there is still a relationship between HE access and income. Figure 8 depicts the share of 18-24 year olds in the top and bottom income quintiles who are enrolled in HE in 2013. (Note 17) On average, while enrollment rate is below 8 percent in the bottom quintile, it surpasses 40percent in the richest quintile. As the following section documents, economic outcomes such as earnings and employment are better for individuals with HE than for those without it. Thus, the fact that higher income households are more likely to enroll in HE (and hence attain better economic outcomes) might exacerbate rather than mitigate economic inequality in the region. 


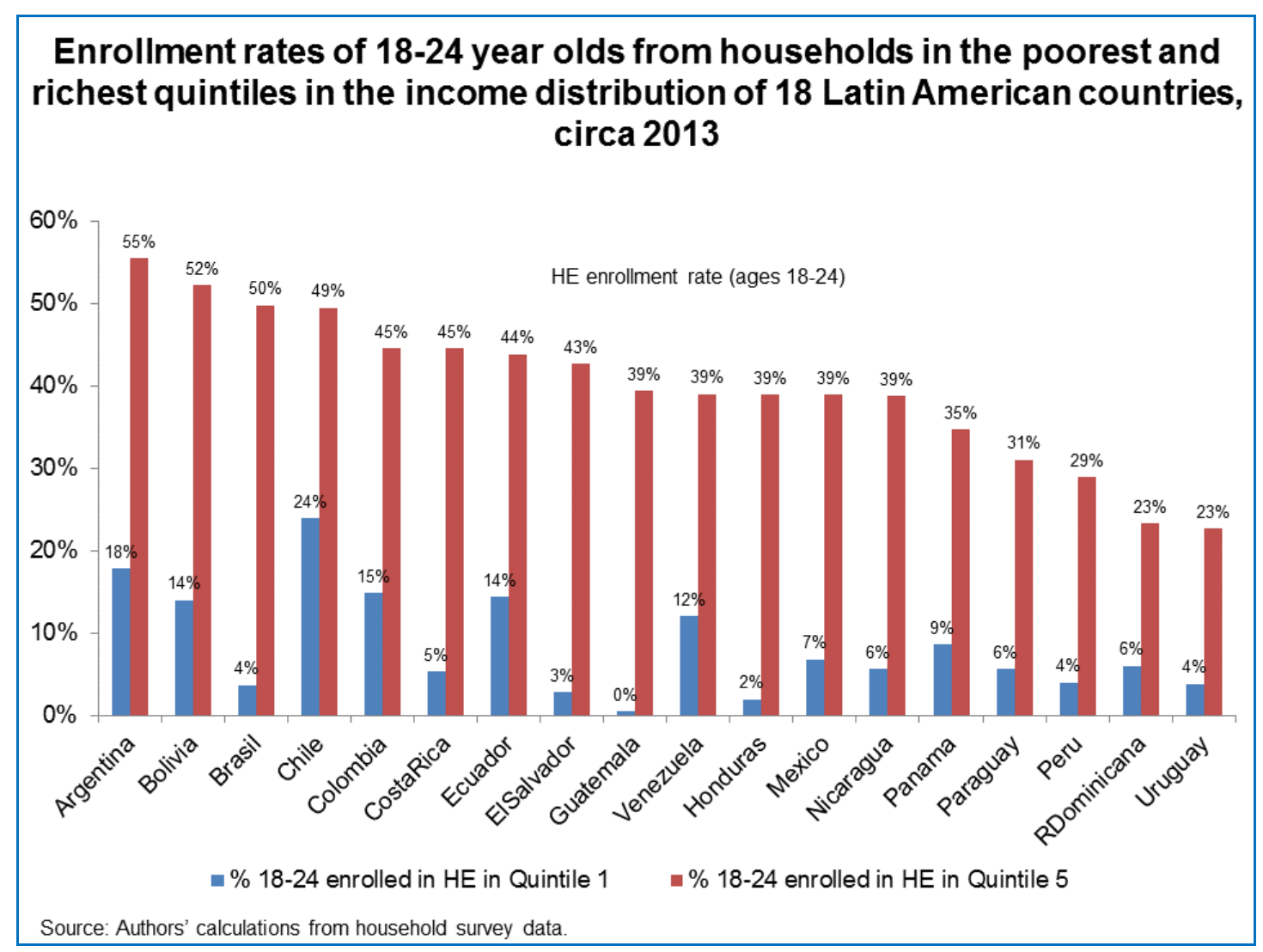

Figure 8.

\section{HE and economic opportunities in LAM}

Several authors have documented that the economic returns to HE relative to primary education have declined in the region since the turn of the century. (Note 18) Figure 9 presents our regional average estimates based on LAM household surveys, (Note 19) and shows that relative returns of HE Higher Education (complete and incomplete) relative to USE have followed broadly an inverted U-shaped trend, increasing during the 1990s and up to the mid- 2000s and declining (slightly) thereafter.

Despite recent declines, the returns to HE remain high. Based on Figure 9, in 2012 returns to complete HE in 2012 are approximately 115 percentage points higher than returns to complete USE, and returns to incomplete HE are approximately 50 percentage points higher than returns to complete USE.

Interestingly, the average wage for those who have ever enrolled in AHE is 1.9 times as high as the average wage in the economy, while the average wage for those who have ever enrolled in THE is 2.1 times as high as the average wage in the economy. A look at country level data -not shown here for brevity- reveals that relative to average wages in the economy, the average wage of HE graduates is highest in Costa Rica and Ecuador, and lowest in Paraguay and Nicaragua. 


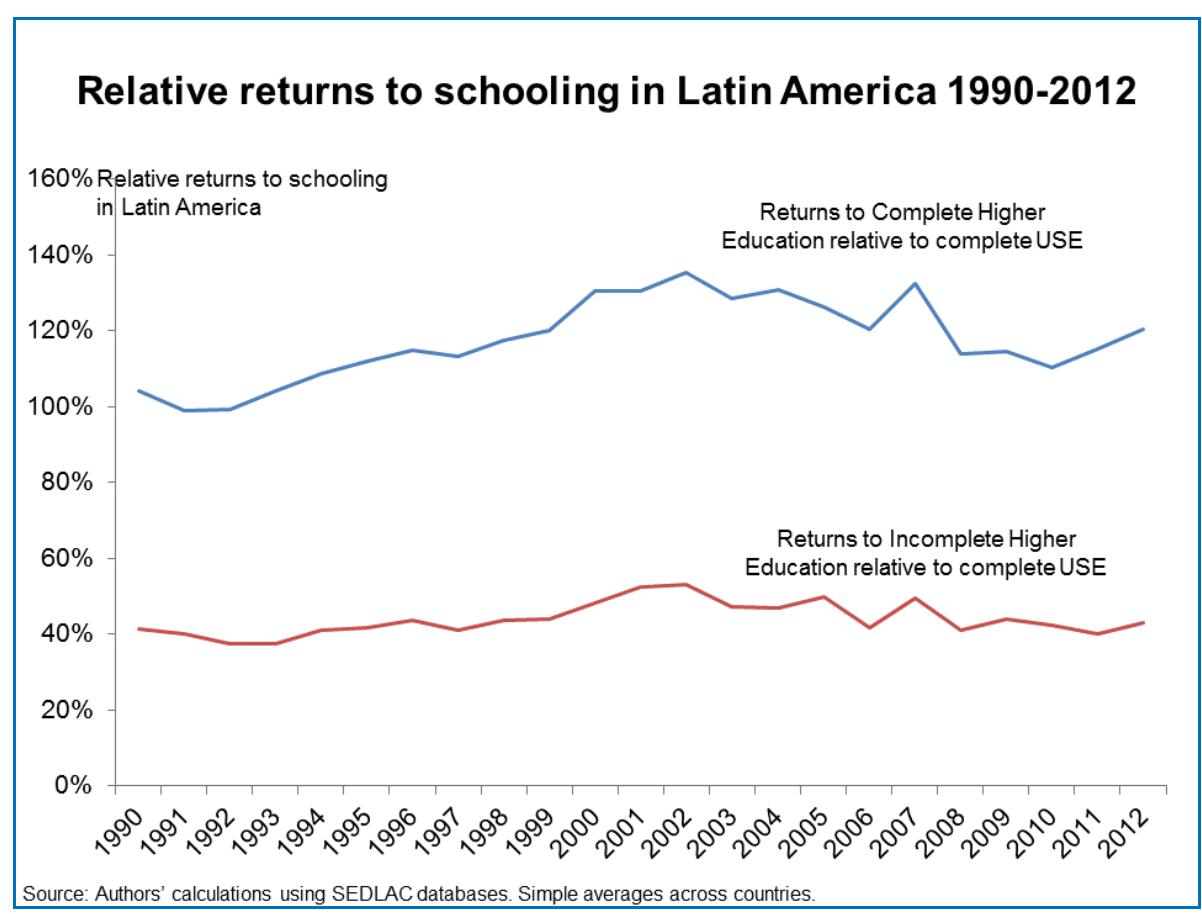

Note: Relative return of complete $\mathrm{HE}$ relative to complete USE = regional average of ( $\exp \left(\mathrm{b} \_\mathrm{CH}-\right.$ b_USE)-1)*100, where b_CH and b_USE are the Mincer regression coefficients on complete HE and complete USE, respectively. Relative returns to incomplete HE were calculated similarly.

Figure 9.

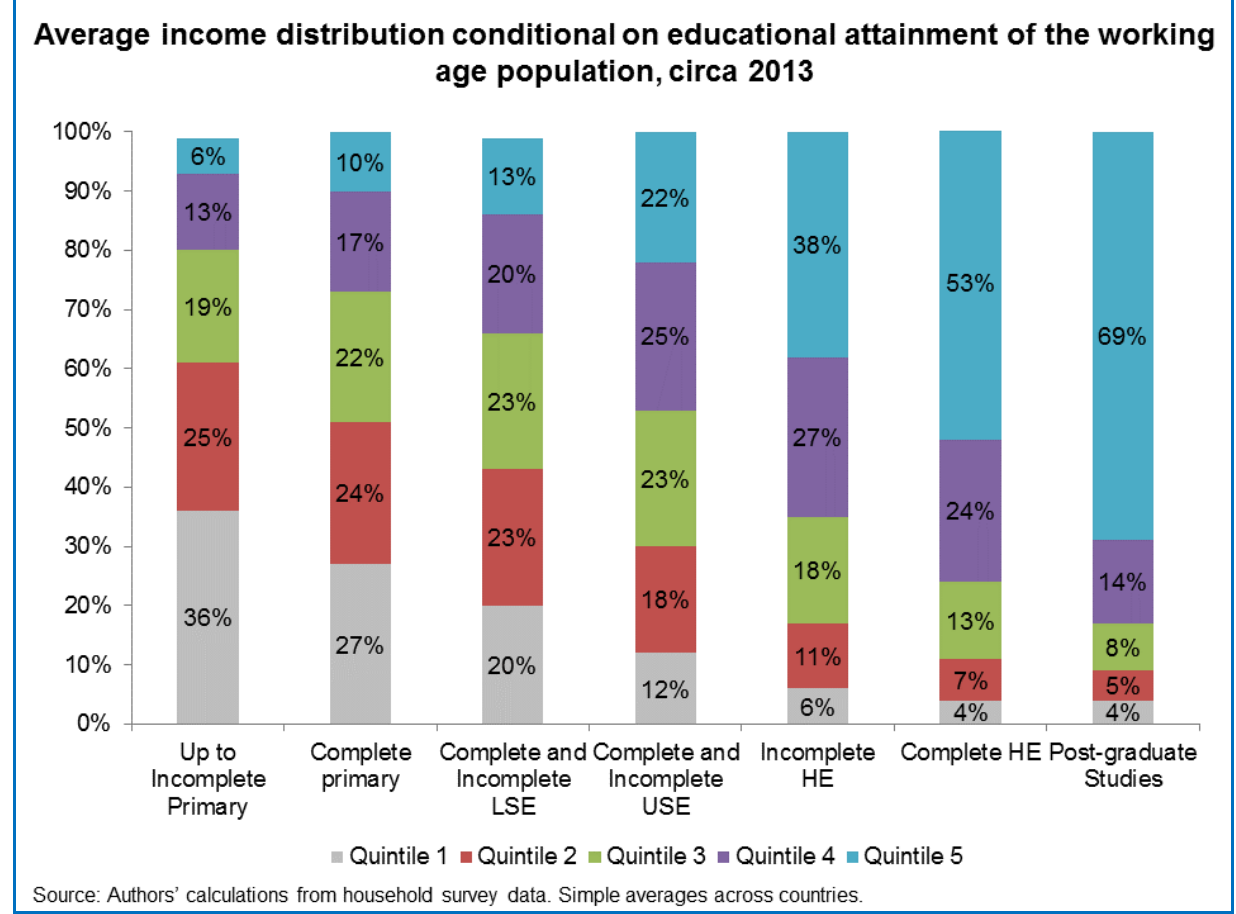

Figure 10. 
Figure 10 shows the distribution of income conditional on educational attainment for the WAP in 2013. As the figure shows, the likelihood of belonging to the top two 40 percent of the income distribution rises with educational attainment. Among individuals who completed USE, 47 percent belong to the top 40 percent, in contrast to 65 and 79 among those with incomplete and complete HE respectively. The probability rises further to 83 percent among those with graduate studies. When we focus exclusively on the top 20 percent of the income distribution, only 22 percent of individuals with complete USE belong to this quintile, in contrast with 38, 53 and 69 percent of individuals with some HE, complete HE, and graduate studies respectively.

These results hold for specific countries as well. Figure 11 shows that at least 60 percent of individuals who have ever enrolled in HE belong to the top two quintiles in each country. Moreover, with the exception of Panama, Peru, Argentina, Venezuela and Bolivia, the majority of WA individuals who have ever enrolled in HE belong to the top quantile.

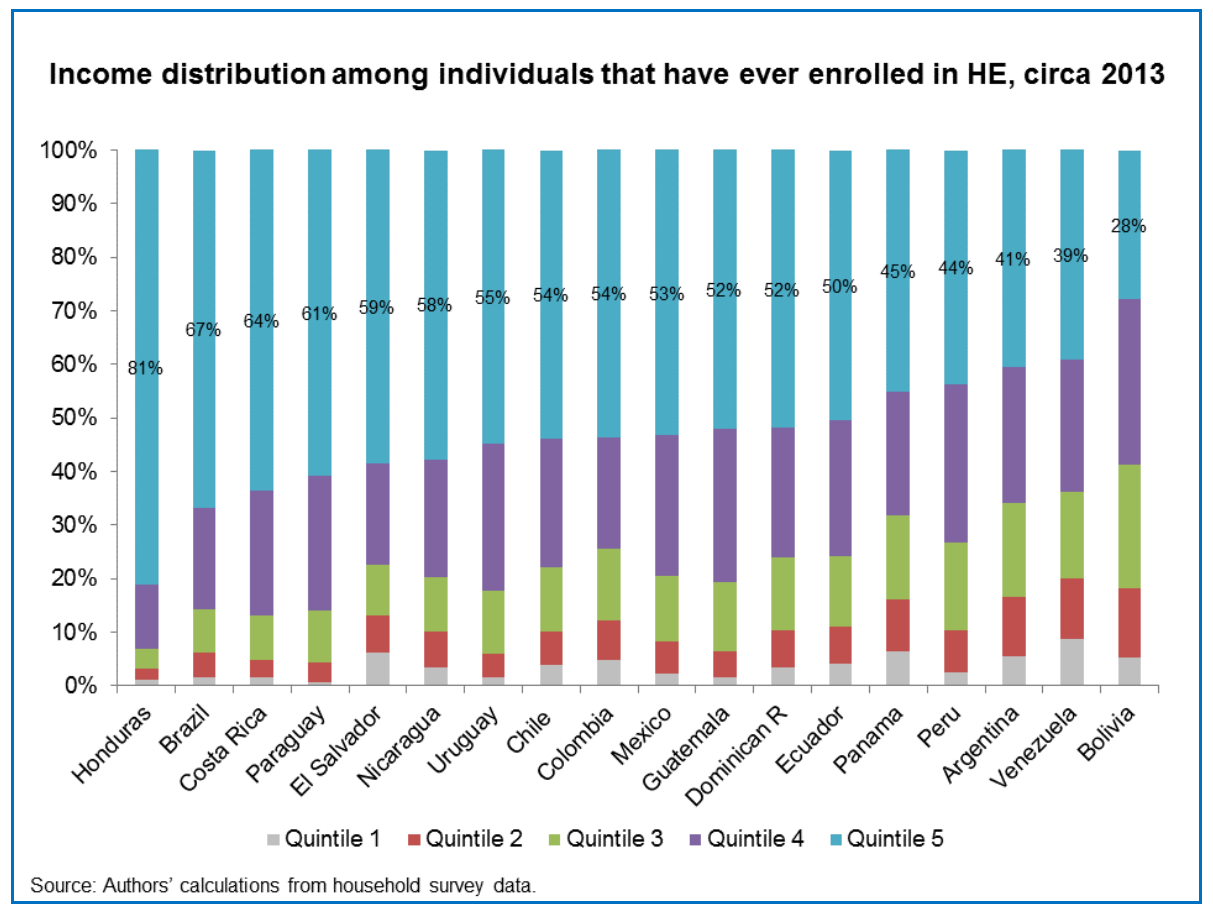

Figure 11.

HE is also associated to different patterns of labor market insertion, as we can see by following a recent cohort (born circa 1982) in Figure 12. We trace the labor market trajectory of these individuals between age 18 (in 2000) and age 30(in 2013). These twelve years are informative of the cohort's initial labor market experience. We classify individuals by their highest educational attainment. While USE graduates have higher labor force participation than HE graduates before age 24, the reverse happens afterwards. This suggests that while earlier entry into the labor force may provide an employment advantage to USE graduates, the advantage vanishes once better educated individuals finish school and join the labor force. Interestingly, Figure 12 shows that labor force participation is substantively higher for individuals with complete HE than for those with incomplete HE, although the gap narrows by age 31 . 


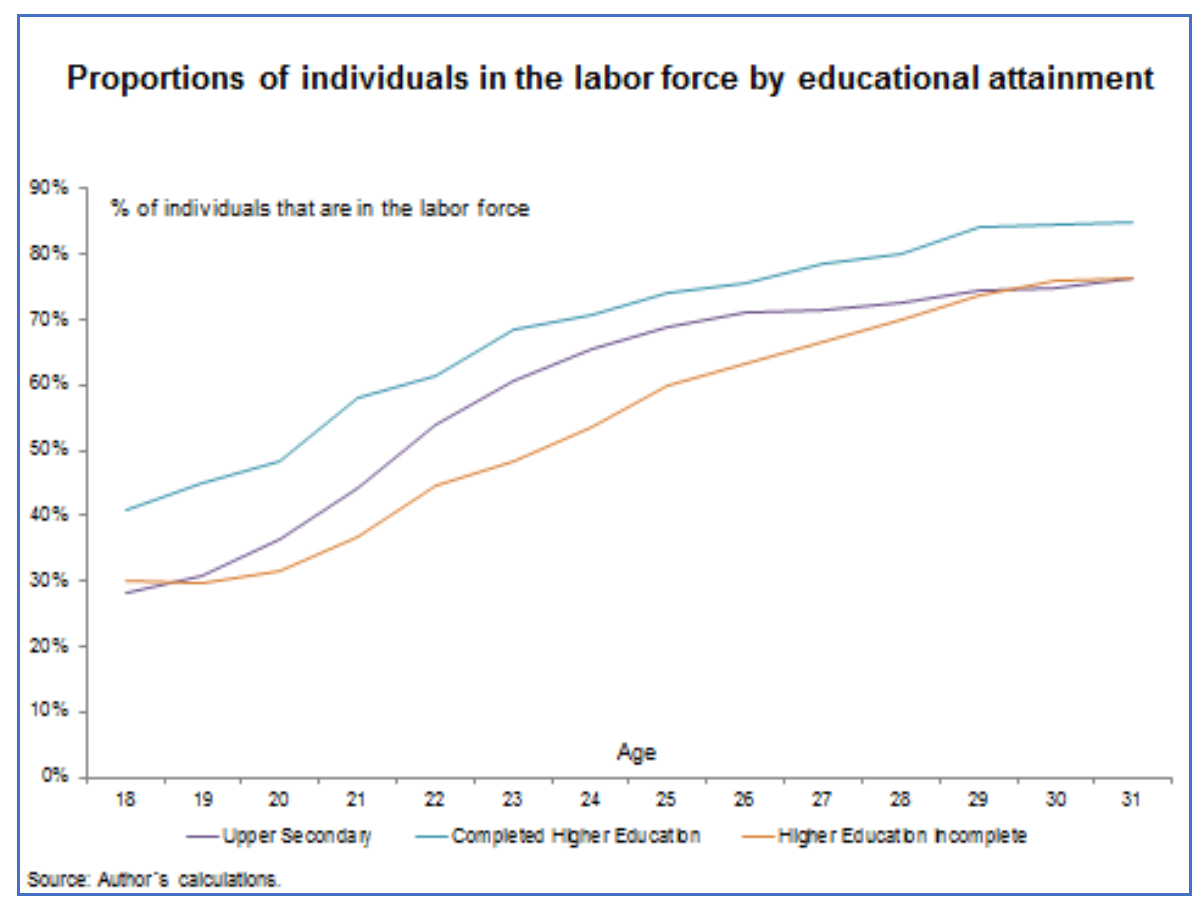

Note: for each educational attainment, percent in the labor force at age $a$ is expressed as the ratio labor force participation at $a /$ labor force participation at 18. Figure depicts averages across countries.

Figure 12.

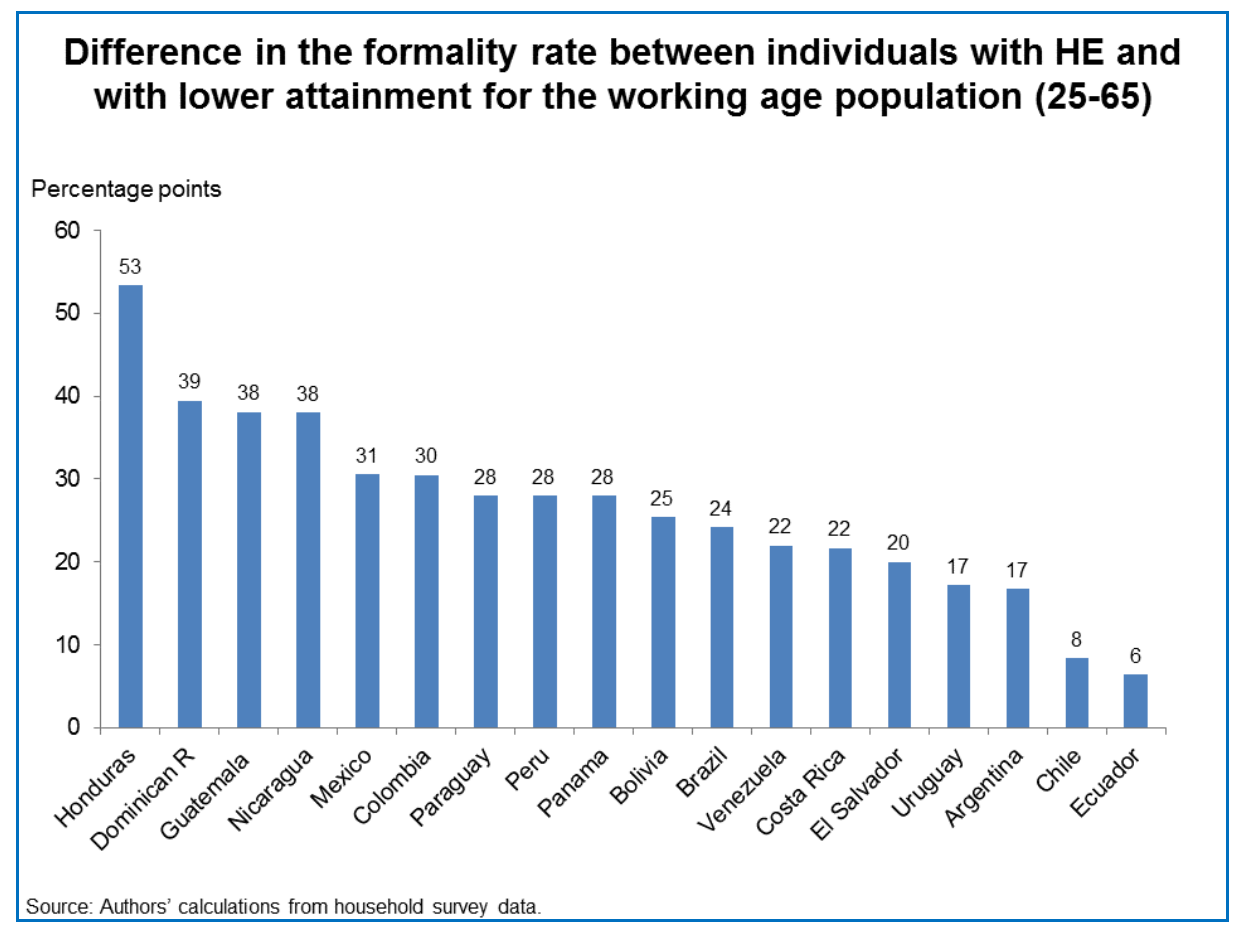

Note: the figure depicts difference in formality rates between individuals who have ever enrolled in HE and those with lower educational attainments.

Figure 13. 
Moreover, HE enrollment is associated with a higher formality rate in the labor market, calculated as the percent of employed individuals in the labor force who are employed in the formal sector. Based on household surveys, while average formality in the labor force in LAM is 52 percent, formality among those with complete HE is 72 percent. This formality advantage persists even when we consider all individuals who have ever enrolled in $\mathrm{HE}$ regardless of completion (their formality rate is 64 percent), including those who have ever enrolled in THE (their formality rate is 66 percent).

Figure 13 shows the difference in formality rates in the WAP between those with at least some HE and those with lower other educational attainments. HE is associated with the highest boost to formality in Honduras, Dominican Republic, Guatemala and Nicaragua, and with the lowest in Ecuador, Chile, Argentina and Uruguay.

\section{Contextual variables and access to $\mathrm{HE}$}

Given the large differences in HE enrollment rates across countries in the region, it is of interest to investigate their association with other variables. In a recent paper, Bentaouet-Kattan and Székely (2015) use a cohort approach similar to ours, and estimate the association between the cohort-level change in USE enrollment over time, and variables such as labor market conditions, socioeconomic composition of new entrants into the schooling system, and returns to USE. Thus, in this section we follow a similar approach for HE enrollment.

Following Bentaouet-Kattan and Székely (2015), we study the share $Y_{c j t}$ of individuals in cohort $c$, country jand time (year) $t$ who have ever enrolled in HE. (Note 20) We refer to this share as "enrollment rate" for the remainder of this section. We explore the association between the change in $Y_{c j t}$ and the change in a group of relevant variables for which we have comparable information across countries and over time. We group these variables as follows: demographic $(D)$ variables representing the "pipeline" of potential students for higher education; macroeconomic $(M)$ variables; returns to $\mathrm{HE}(R)$; and other labor market conditions $(L)$. Assuming a linear form yields the following:

$$
\Delta \mathrm{Y}_{\mathrm{ct}}=\alpha_{0}+\beta_{1} \Delta \mathrm{D}_{\mathrm{jt}}+\beta_{2} \Delta \mathrm{M}_{\mathrm{jt}}+\beta_{3} \Delta \mathrm{R}_{\mathrm{jt}}+\beta_{4} \Delta \mathrm{L}_{\mathrm{jt}}+\varepsilon_{\mathrm{cjt}}
$$

where $\Delta$ represents the change in the variable of interest between two consecutive episodes (see more below); $\mathrm{D}_{\mathrm{jt}}, \mathrm{M}_{\mathrm{j} t}, \mathrm{R}_{\mathrm{jt}}$, and $\mathrm{L}_{\mathrm{jt}}$ are row vectors representing country-year demographic conditions, macroeconomic environment, HE education returns, and labor market conditions respectively; $\beta_{i}, i=1 \ldots 4$ are column vectors representing the parameters of interest, and $\varepsilon$ is the error term. We assume $\mathrm{E}\left(\varepsilon^{*}{ }_{\mathrm{cjt}} \mid \mathrm{D}_{\mathrm{jt}}, \mathrm{M}_{\mathrm{jt}}, \mathrm{R}_{\mathrm{jt}}, \mathrm{L}_{\mathrm{jt}}\right)=\mathrm{E}\left(\varepsilon^{*}{ }_{\mathrm{cjt}}\right)=0$.

To construct the dependent variable, we follow each cohort as it transitions from USE to HE (going from approximately 16-17 years old to 21-24 years old, with the exact age range being a function of the country's official exit ages from USE and HE). For a country and cohort, an "episode" is the change in HE enrollment rate between two years for which data are available. Consider, for instance, the case of the 1978 cohort in Mexico. These individuals are approximately 16 years old in 1994, and 24 years old in 2002. Since Mexican data are 
available for 1994, 1996, 1998, 2000 and 2002, for each of these years we calculate the percent of individuals from the 1978 cohort that have ever enrolled in HE. This gives us four episodes for the cohort: 1994-1996, 1996-1998, 1998-2000, and 2000-2002. We calculate the percent of individuals in the cohort who have ever enrolled in HE as of 1994 and as of 1996, and calculate the difference between the two percentages for the 1994-1996 episode. We proceed similarly with the remaining episodes. In total, we observe 773 episodes for different cohorts in the pooled data of the 18 countries for which data are available between the early 1980s and 2013, and estimate (1) using all episodes.

Table 2. Cohort-level changes in HE enrollment

Dependent variable: Cohort-level change in HE enrollment rate (HE enrollment rate $=$ percent of individuals in the cohort who have ever enrolled in HE)

\begin{tabular}{|c|c|}
\hline \multirow[t]{2}{*}{ Inflation, consumer prices (annual \%), t-(t-1) } & 0.121 \\
\hline & $(0.254)$ \\
\hline \multirow[t]{2}{*}{$\begin{array}{l}\text { GDP per capita, PPP (constant } 2005 \text { international \$), } \\
\mathrm{t} /(\mathrm{t}-1)\end{array}$} & -0.009 \\
\hline & $(0.016)$ \\
\hline \multirow[t]{2}{*}{$\begin{array}{l}\text { Wage ( } 35-45 \text { years), PPP (constant } 2005 \text { international } \\
\$), t /(t-1)\end{array}$} & -0.008 \\
\hline & $(0.031)$ \\
\hline \multirow[t]{2}{*}{ Female labor participation rate ( $35-45$ years), $\mathrm{t}-(\mathrm{t}-1)$} & $0.313^{*}$ \\
\hline & $(0.157)$ \\
\hline \multirow{2}{*}{ Male labor participation rate (35-45 years), $\mathrm{t}-(\mathrm{t}-1)$} & $-0.209 * * *$ \\
\hline & $(0.066)$ \\
\hline \multirow[t]{2}{*}{ Unemployment rate ( $35-45$ years), t-(t-1) } & 0.065 \\
\hline & $(0.097)$ \\
\hline \multirow[t]{2}{*}{ Formality rate ( $35-45$ years), $\mathrm{t}-(\mathrm{t}-1)$} & $0.105^{*}$ \\
\hline & $(0.056)$ \\
\hline \multirow[t]{2}{*}{$\begin{array}{lll}\text { Returns to tertiary education/Returns to Upper } \\
\text { Secondary ( } 35-45 \text { years), } \mathrm{t}-(\mathrm{t}-1)\end{array}$} & $0.012 * *$ \\
\hline & $(0.004)$ \\
\hline \multirow[t]{2}{*}{ Upper Secondary completition rate, $\mathrm{t}-(\mathrm{t}-1)$} & $0.356^{* * *}$ \\
\hline & $(0.053)$ \\
\hline \multirow[t]{2}{*}{ Constant } & 0.016 \\
\hline & $(0.014)$ \\
\hline Observations & 249 \\
\hline R-squared & 0.478 \\
\hline \multicolumn{2}{|l|}{ Robust standard errors in parentheses } \\
\hline \multicolumn{2}{|l|}{$* * * \mathrm{p}<0.01, * * \mathrm{p}<0.05, * \mathrm{p}<0.10$} \\
\hline${ }^{\wedge}$ Preferred econometric model $1 \%$ & \\
\hline
\end{tabular}

The independent variables represent changes during each episode -between the two same 
years for which HE enrollment is calculated. We measure the change in demographic conditions with the cohort's change in the USE completion rate. Using household surveys, we calculate USE completion rate as the fraction of individuals who complete USE relative to those who started it. We measure the change in macroeconomic conditions with the change in inflation rate and with the percent change in PPP-adjusted GDP per capita, both calculated based on the 2015 World Development Indicators. We measure the change in labor market conditions with the percent change in PPP-adjusted average wages, the change in female labor force participation, the change in male labor force participation, the change in unemployment rate, the change in formality rate, (Note 21) and the change in HE returns relative to USE. We calculate all changes in labor market conditions using household survey data for the 35-45 year old range.

Table 2 presents the regression results of estimating the relation through OLS, with Huber-corrected standard errors, and standard errors clustered at the country level. For the dependent and independent variables we always divide the change observed by the length of the spell in question to control for the fact that spell sizes vary by country depending on the years for which household surveys are available. As can be seen, the independent variables characterizing the demographic, macroeconomic and labor market conditions account for about 48 percent of the variation in HE conditional enrollment.

In the regressions we find a positive and significant association between change in $\mathrm{HE}$ enrollment rates and percent change in GDP per capita. This suggests that an increase of per-capita resources in the economy might have an income effect that allows a greater fraction of USE graduates to enroll in HE, holding other things constant. While the coefficient on inflation is negative, it is not significant. 
Table 3. Coefficient Interpretation

\begin{tabular}{|c|c|c|c|c|}
\hline Independent Variable & Coefficient & Mean value & Economic value & $\begin{array}{c}\text { Marginal effect of } \\
\text { 1\% increase on } \\
\text { HE }\end{array}$ \\
\hline Change in the Inflation Rate & 0,121 & $-0,0027$ & $-0,033 \%$ & $-0,01 \%$ \\
\hline$\%$ Change in the value of PPP adjusted GDP per capita & 0,009 & 0,0101 & $0,009 \%$ & $0,00 \%$ \\
\hline \multicolumn{5}{|l|}{$\%$ Change in the value of PPP adjusted wages for the $35-45$} \\
\hline age group & $-0,008$ & 0,0061 & $-0,005 \%$ & $0,00 \%$ \\
\hline \multicolumn{5}{|l|}{ Change in the female labor force participation rate in the } \\
\hline $35-45$ age group & 0,313 & 0,0066 & $0,207 \%$ & $0,08 \%$ \\
\hline \multicolumn{5}{|l|}{ Change in the male labor force participation rate in the $35-45$} \\
\hline age group & $-0,209$ & 0,0005 & $-0,011 \%$ & $0,00 \%$ \\
\hline Change in the unemployment rate in the $35-45$ age group & 0,065 & 0,0032 & $0,021 \%$ & $0,01 \%$ \\
\hline Change in the labor formality rate in the $35-45$ age group & 0,105 & 0,0044 & $0,047 \%$ & $0,02 \%$ \\
\hline \multicolumn{5}{|l|}{ Change in the HE/USE relative returns to education in the } \\
\hline $35-45$ age group & 0,012 & 0,0003 & $0,000 \%$ & $0,00 \%$ \\
\hline \multicolumn{5}{|l|}{ Change in the USE completio rate between current and } \\
\hline Constant & 0,016 & 0,016 & 0,016 & 0,016 \\
\hline Total & & & $2,66 \%$ & $2,00 \%$ \\
\hline
\end{tabular}

Source: Author's calculations.

Interestingly, we find a positive and significant association between changes in female labor force participation and changes in HE enrollment rate, which might be a sign that better labor market prospects provide incentives for achieving higher education levels which presumably can increase the probabilities of accessing these opportunities specially for women (an income effect). However, the association is also positive, although negative in the case of male labor force participation. The interpretation in this case is that for males, higher employment probabilities can increase the opportunity cost of continuing in the education system and thus provides incentives for leaving school and enrolling in the labor market (a substitution effect).

As well, we find a slightly significant positive association between the formality rate and HE demand, indicating greater HE demand as job "quality" (as measured by formality status) rises. Note that the relationship of HE demand with the wage and unemployment levels are not significant, but changes in the returns to HE relative to those in USE are positive and highly significant.

Finally, we find a positive and significant association between change in USE completion rates and change in HE demand. This indicates that HE demand rises with the growth in the pipeline of qualified students.

Table 3 illustrates the magnitude of the associations. For each independent variable, column (1) shows the coefficient, column (2) shows the sample mean, and column (3) shows the 
predicted increase in HE enrollment rate when the independent variable rises by an amount equal to the sample mean. Note that for each independent variable, column (3) is the product of columns (1) and (2). During the sample period, the average HE enrolment rate is equal to 17.50 percent, and the average change in HE enrollment rate (i.e., the average value of the dependent variable) is equal to 1.72 percentage points.

The table shows that the dependent variable is most strongly associated with changes in USE completion rates. An increase in USE completion rate equal to one percentage point is associated with an increase in HE enrollment rate equal to 0.31 percentage points. In contrast, an increase in GDP growth equal to one percentage point is associated with an increase in HE enrollment rate equal to 0.003 . A similar increase associated with an additional percentage point in female labor force participation is equal to 0.078 percentage points, and of 0.004 points for male labor force participation. For a cohort whose change in USE completion rate between episodes is equal to the sample mean (equal to 2.32 percentage points), the predicted increase in HE enrollment rates is equal to 0.827 percentage points, or 48 percent of the sample average change in HE enrollment $(0.48=0.827$ / 1.72).

Taken together, our regression results suggest that a greater pipeline of qualified students, greater economic growth and improved labor market prospects for women have been strongly correlated with the increase in conditional HE enrollment in the region. Nonetheless, the factor most strongly associated with HE enrollment growth has been the USE completion rate growth. In other words, growth in the "pipeline" of HE students seems to have been a critical correlate of the HE expansion.

This finding has two important implications. First, given the region's stagnant USE completion rates, it is likely that HE enrollment rates will remain flat in the near future in the absence of other policies. Second, once the region approaches the USE completion rates of the developed world, it will need to find alternative mechanisms to raise HE enrollment. Thus, the ability to attract an increasing fraction of USE graduates into HE will become all the more important as countries improve their USE completion rates. Our regression results indicate that macroeconomic and labor market conditions are indeed associated with HE enrollment rates; the ability to attract students into HE may well be related to those factors as well as to specific HE policies.

\section{Conclusions}

In this paper we use household survey data to study trends in HE enrollment and completion in 18 Latin American countries over the last 35 years, with a special emphasis on the behavior of recent cohorts. An important contribution of our paper is the ability to distinguish among two main types of HE programs, namely academic and technical programs.

We find that HE enrollment has grown substantively for recent cohorts; today, about one in four young individuals has been enrolled in HE. However, only half of them has completed HE. Relative to total enrollment in HE, completion rates have fallen in the last twenty years. More individuals choose the academic rather than the technical track, and HE expansion has been significantly higher among females than males. 
HE access is highly concentrated among the highest quintiles of the income distribution. Since HE access is associated with better economic outcomes over the life cycle, this access disparity might accentuate the already large inequality prevailing in the region. Both the disparity in access to $\mathrm{HE}$ and the low HE completion rates suggest that the positive economic outcomes associated with HE (in terms of returns, wages, employment and formality) documented in this paper are not reached by those who do not enroll in HE, and are reached only partly by those who start but do not complete HE.

By following the schooling trajectory of several cohorts we find that HE expansion is closely related to the rise in USE completion rates in the region. Thus, one mechanism to increase HE enrollment is to continue expanding the "pipeline" of USE graduates. Yet another mechanism is to increase the rate of USE graduates who enroll in HE. In fact, once the region reaches USE graduation rates similar to those in the developed world, this mechanism will be critical to future HE expansions.

\section{Acknowledgement}

The author thanks Ciro Avitabile, Laura Chioda, Maria Marta Ferreyra, Julian Messina and workshop participants at the World Bank for useful comments, and Pamela Mendoza for excellent research assistance

\section{References}

Adelman, M., \& M. Székely. (2015). School dropout: unresolved issues and new challenges for education progress in Central America, The World Bank, Washington DC.

Aedo, Christian, \& Ian Walker. (2012). Skills for the 21st Century in Latin America and the Caribbean.World Bank, Washington, DC. https://doi.org/10.1596/978-0-8213-8971-3

Alfonso, M., M.S. Bos, J. Duarte, y C. Rondón. (2012). Panorama General de la Educación en América Latina y el Caribe, Capítulo 1 en M. Cabrol y M. Székely. Educación para la Transformación, Banco Inter Americano de Desarrollo.

Bassi, M., M. Busso, Sergio Urzúa, \& J. S. Muñoz. (2013). Is the Glass Half Empty of Half Full?: school enrollment, graduation and drop out rates in Latin America, IDB Working Paper Serioes No. IDB-WP-492, Inter-American Development Bank.

Bentaouet-Kattan, R., \& Székely, M. (2015). Analyzing the Dynamics of Upper Secondary Schooling in Latin America: A Cohort Approach, World Bank Policy Research Working Paper 7223, Washington.

Bloom, David. (2006). Cannig, David and Chan, Kevin.Higher Education and Economic Development in Africa. Harvard University. February

Browning, M., Deaton, A. \& Irish, M. (1985). A Profitable Approach to Labour Supply and Commodity Demands Over the Life Cycle. Econometrica, 53(3), 503-544.

Cuadra, Ernesto, \& J.M. Moreno. (2005). Expanding Opportunities and Building Competencies for Young People: A New Agenda for Secondary Education, Directions in 
Development, The World Bank, Washington DC.

Deaton, A. (1997). The Analysis of Household Surveys: A Microeconometric Approach to Development Policy. Johns Hopkins University Press, Baltimore, Maryland. https://doi.org/10.1596/0-8018-5254-4

Gasparini, L. et al. (2011). Educational Upgrading and Returns to Skills in Latin America. Policy Research Working Paper 5921. Washington, DC, United States: World Bank.

Gyimah-Brempong, Kwabena, O. Paddison y W. Mitiku. (2006). Higher Education and Economic Growth in Africa. Journal of Development Studies, 42(3), 509-529.

Hanushek, E., \& L. Woessmann. (2010). The Economics of International Differences in Education Achievement, IZA Discussion paper 4925, Bonn, May. https://doi.org/10.1016/j.jdeveco.2012.06.004

Hanushek, Eric A., \& LudgerWoessmann. (2012). Schooling, Educational Achievement, and the Latin American Growth Puzzle. Journal of Development Economics, 99(2), 497-512.

Heckman, J., \& P. Lafontaine. (2010). The American High School Graduation Rate: Trends and Levels. Review of Economic and Statistics, 92(2), 244-262. https://doi.org/10.1162/rest.2010.12366

Kapur, Devesh, \& Crowley, Megan. (2008). Beyond the ABCs: Higher Education and Developing Countries. Center for Global Development, CGDEV.Working Paper No. 139. Februar.

Ludvall, Bengt-Åke. Higher Education, Innovation and Economic Development Department of Business Studies Aalborg University, Denmark.

Manacorda, Marco, Sánchez-Páramo, Carolina, \&Schady, Norbert. (2010). Changes in returns to education in Latin America: The role of demand and supply of skills. Industrial and Labor Relations Review, 307-326. https://doi.org/10.1177/001979391006300207

Moreno-Brid, Juan Carlos y Ruiz-Nápoles, Pablo. (2009). La educación superior y el desarrollo económico en América Latina. Sede Subregional de la CEPAL en México. CEPAL, México D.F., 29 enero de.

Murnane, R.J. (2013). U.S. High School Graduation Rates: Patterns and Explanations. Journal of EconomicLiterature, 51(2), 370-422. https://doi.org/10.3386/w18701

Organización de Estados Iberoamericanos (OEI). (2010). 2021: Metas Educativas, Madrid.

UNESCO. (2009). World Conference on Higher Education: The New Dynamics of Higher Education and Research for Societal Change and Development. UNESCO, Paris 5-8 July.

United Nations Educational, Scientific and Cultural Organization. UNESCO. (2005). Secondary Education Reform: Towards a Convergence of Knowledge Acquisition and Skills Development, UNESCO, Paris.

World Bank. (2000). La Educación Superior en los Países de Desarrollo: Peligros y Promesas. 
Banco Internacional para la Reconstrucción y el Desarrollo, Banco Mundial, Washington D.C.

World Bank. (2012). Putting Higher Education to Work - Skills and Research for Growth in East Asia. World Bank East Asia and Pacific, Regional Report. The International Bank for Reconstruction and Development / The World Bank, Washington, DC.

\section{Notes}

Note 1. Current challenges in primary and lower secondary education include reducing retention and over age (see, for instance Bassi et al 2014), and increasing education quality (Hanushek and Woessmann, 2010 and 2012).

Note 2. The USE dropout rate is the fraction of students who do not finish USE relative to those who started it.

Note 3. The low rates of USE completion have been a growing concern in Latin America (OEI 2010, UNESCO 2005) as well as in other regions of the world (see, for instance, Cuadra and Moreno 2005, Heckman and Lafontaine 2010, and Murnane 2013).

Note 4. This role has been vastly documented in the literature. See, for instance, World Bank (2000, 2012), Lundvall etal (2007), Kapurand Crowley (2008), and UNESCO (2009). Gyimah-Brempong, et.al (2006) and Bloom et al. (2006), among others, have documented that even in low-income African countries, HE has an increasing potential to drive economic growth; these studies estimate the that economic effects of increasing HE are twice as large as those from investing in physical capital. For Latin America, Moreno and Ruiz (2009) document the economic impact that HE had on innovation, competitiveness and productivity during of the region's opening of the economies in 1980s and 1990s. These authors argue that, in addition, HE has positive social effects such as helping consolidate democracy and institutions.

Note 5. An individual has "access" to an educational level when she enrolls in it, regardless of whether she completes it or not.

Note 6. See Deaton for a description of these types of surveys, and their use in research on a variety of issues.

Note 7. Relative to Censuses, household surveys have the advantages of being produced much more frequently in LAM (Censuses usually take place every ten years, while household surveys take place annually) and of providing much richer information on schooling.

Note 8. Household surveys from Brazil do not allow for the classification of HE programs into AHE and THE.

Note 9. In the case of Argentina particularly, there have been significant changes in the representativeness and coverage of household surveys, with only urban coverage up to the year 2000 and national coverage thereafter. Since the majority of the population resides in urban areas, the bias introduced by this difference is ameliorated over time. However, it would still be expected that HE enrollment rates -and this is the case for all education levelswould be overestimated prior to 2000 since rural areas tend to have lower education access. We use the full series of household surveys for the descriptive sections of this paper, and incorporate a dummy variable for surveys prior to 2000 in the econometric estimations to acknowledge this difference. 
Note 10. We follow UNESCO's 1997 ICSED classification whenever possible. The classification states the official age bracket during which an individual should attend school by education level. The definitions are found at http://www.uis.unesco.org/Education/ISCEDMappings/Pages/default.aspx. Other efforts to homogenize household survey data for research on education have been conducted by the Economic Commission for Latin America and the Caribbean (ECLAC) and the SEDLAC (Socio Economic Data Base for Latin America and the Caribbean) household survey data base developed under the auspices of the World Bank. For this paper we have accessed the original household surveys in order to process the data according to the classifications and definitions mentioned above, and to guarantee comparability over time and across countries in the definitions of AHE and THE.

Note 11. All LAM level results refer to the unweighted average across the 18 countries for which we have data. Since not all countries have surveys for the same years, we interpolate between observations when needed in order to produce a balanced panel. In cases such as Figure 1 where data for two specific years are presented, we assign to each year the average of that year, the one preceding and the one after, in order to smooth out the figures.

Note 12. A person with "some HE" has enrolled in HE but has not completed it. A person with "at least some HE" has enrolled in HE; she may have completed it or not. We use similar criteria for other educational levels. A person's highest attainment is the highest educational level that she has completed.

Note 13. The regional averages when disaggregating HE into AHE and THE do not include Brazil, since for this particular country the household survey data contains information on HE enrollment and completion, but does not distinguish between the two options.

Note 14. Of course, cohort composition can change over time and thus affect these averages. Specifically, if mortality, emigration, or immigration varies over time for a particular cohort, the averages might not reflect the profile of the same group of individuals over time and can bias our conclusions. For instance, if those migrating outside of the country at prime age have relatively lower or higher education levels that those remaining in the country, the average years of schooling of those observed in the cohort might be biased upward or downward, respectively. Unfortunately we lack the data necessary to correct for compositional changes for the countries in LAM, but we believe the overall picture is still illustrative. In the case of mortality, if rates are higher for less educated individuals, figures such as Figure 1would be upward biased.

Note 15. For each cohort and year, the figure shows the unweighted average across countries for the fraction of individuals enrolled in school.

Note 16. This completion rate includes all individuals who ever completed USE, regardless of age at completion.

Note 17. Note that this is a different exercise from that performed in Section 2.1. Here we examine the correlation between the household income of a person aged 18-24 and her HE access. In contrast, in Section 2.1 we examined the correlation between a person's educational attainment and her future income, once she joins the WAP. Loosely speaking, here we look at income as a possible cause of HE enrollment, whereas in Section 2.1 we look at income as a possible consequence of HE enrollment. 


\section{NI Macrothink}

Note 18. Manacorda, Sánchez Páramo and Schady (2010) documented rising returns to HE during the 1980s and 1990, and declining returns after 2000. Bassi, Busso and Nuñez (2013), Aedo and Walker (2012) and Gasparini etal (2011) document similar trends. Some possible explanations for the decline in HE returns include the increase in the supply of workers with $\mathrm{HE}$ and/or their lower ability, the quality decline in $\mathrm{HE}$ as a result of the rapid expansion of HE since the early 2000s, and the inability of HE institutions to supply the skills required by the market. Gasparini etal (2011) argue that the increased demand and prices for commodities in world markets raised the relative demand for unskilled labor and thus lowered the returns to HE.

Note 19. We estimate these returns through Mincer regressions using data on males and females aged 35-45. For each country and year, we regress log wages on the following independent variables: education dummies, potential experience $(=$ age $-6-$ years of schooling), potential experience squared and gender. We include a sample selection term for labor force participation that is a function of the same independent variables. The excluded category in th education dummies is the "no schooling" group; the rest are primary or less, Lower Secondary (complete or incomplete), Upper Secondary (complete or incomplete) and Higher Education (complete or incomplete) For each (country, year), we calculate the difference in returns to complete HE relative to complete USE as (exp(b_CHE - b_USE) 1 )*100, where b_CHE is the Mincer regression coefficient on complete HE and b_USE is the Mincer regression coefficient on complete USE. We calculate the difference in returns to incomplete HE relative to complete USE in a similar fashion. Finally, for each year we average these differences in returns across countries; these are the averages depicted in Figure 9.

Note 20. This includes all individuals in the cohort who have ever enrolled in HE by time $t$. In particular, it includes those who have enrolled and already graduated, those who are still enrolled at time $t$, and those that have enrolled but subsequently dropped out. For a given cohort, the enrollment rate changes over time as additional individuals enroll in HE.

Note 21. We consider an employee "formal" if her job provides her with law-mandated benefits. 
Appendix. Table A.1

\begin{tabular}{|c|c|c|c|c|c|c|c|c|c|c|c|c|c|c|c|c|c|c|c|c|c|c|}
\hline \multicolumn{8}{|l|}{ Country } & \multicolumn{14}{|c|}{ Years for which household survey is available } & \multirow{2}{*}{$\begin{array}{c}\text { Total } \\
\text { \# of } \\
\text { years } \\
21\end{array}$} \\
\hline Venezuela & 1981 & 1982 & 1983 & 1985 & 1986 & 1988 & 1989 & 1990 & 1992 & 1993 & 1995 & 1996 & 1997 & 1998 & 1999 & 2000 & 2001 & 2003 & 2004 & 2006 & 2007 & \\
\hline Brasil & 1981 & 1983 & 1986 & 1988 & 1992 & 1993 & 1995 & 1996 & 1997 & 1998 & 1999 & 2001 & 2002 & 2003 & 2004 & 2008 & 2009 & & & & & 17 \\
\hline Argentina & 1980 & 1996 & 1998 & 2000 & 2001 & 2002 & 2003 & 2004 & 2005 & 2006 & 2007 & 2008 & 2009 & 2010 & 2011 & & & & & & & 15 \\
\hline Honduras & 1989 & 1992 & 1996 & 1997 & 1998 & 1999 & 2001 & 2002 & 2003 & 2005 & 2007 & 2008 & 2009 & 2010 & 2011 & & & & & & & 15 \\
\hline Panamá & 1991 & 1995 & 1996 & 1997 & 1998 & 1999 & 2001 & 2002 & 2003 & 2004 & 2006 & 2007 & 2008 & 2009 & 2010 & & & & & & & 15 \\
\hline Peru & 1985 & 1991 & 1994 & 1996 & 2000 & 2001 & 2002 & 2003 & 2004 & 2005 & 2006 & 2008 & 2009 & 2010 & 2011 & & & & & & & 15 \\
\hline Paraguay & 1993 & 1994 & 1995 & 1996 & 1997 & 1998 & 1999 & 2000 & 2002 & 2003 & 2004 & 2008 & 2009 & 2010 & 2011 & & & & & & & 15 \\
\hline Colombia & 1980 & 1986 & 1989 & 1996 & 1997 & 1998 & 1999 & 2000 & 2003 & 2006 & 2007 & 2008 & 2009 & 2010 & & & & & & & & 14 \\
\hline Costa Rica & 1987 & 1989 & 1991 & 1993 & 1995 & 1997 & 1998 & 2000 & 2001 & 2002 & 2003 & 2004 & 2009 & 2010 & & & & & & & & 14 \\
\hline El Salvador & 1989 & 1992 & 1995 & 1996 & 1997 & 1998 & 1999 & 2000 & 2001 & 2002 & 2003 & 2004 & 2007 & 2008 & & & & & & & & 14 \\
\hline Uruguay & 1989 & 1992 & 1995 & 1997 & 1998 & 2001 & 2002 & 2003 & 2004 & 2005 & 2006 & 2007 & 2010 & 2011 & & & & & & & & 14 \\
\hline México & 1984 & 1989 & 1992 & 1994 & 1996 & 1998 & 2000 & 2002 & 2004 & 2005 & 2006 & 2008 & 2010 & & & & & & & & & 13 \\
\hline \multicolumn{23}{|l|}{ Dominican } \\
\hline Rep. & 1995 & 1996 & 1997 & 2000 & 2001 & 2002 & 2003 & 2004 & 2007 & 2009 & 2010 & 2011 & & & & & & & & & & 12 \\
\hline Chile & 1987 & 1990 & 1992 & 1994 & 1996 & 1998 & 2000 & 2003 & 2006 & 2009 & & & & & & & & & & & & 10 \\
\hline Ecuador & 1995 & 1998 & 2000 & 2001 & 2003 & 2004 & 2008 & 2009 & 2010 & 2011 & & & & & & & & & & & & 10 \\
\hline Bolivia & 1995 & 1996 & 1997 & 1999 & 2001 & 2002 & 2008 & & & & & & & & & & & & & & & 7 \\
\hline Guatemala & 1998 & 2000 & 2004 & 2006 & 2009 & 2010 & 2011 & & & & & & & & & & & & & & & 7 \\
\hline Nicaragua & 1993 & 1998 & 2001 & 2005 & 2009 & 2010 & & & & & & & & & & & & & & & & 6 \\
\hline
\end{tabular}

Source: Extended data bank of household surveys. 